\title{
Stand management optimization - the role of simplifications
}

\author{
Timo Pukkala ${ }^{1 *}$, Erkki Lähde ${ }^{2}$ and Olavi Laiho ${ }^{2}$
}

\begin{abstract}
Background: Studies on optimal stand management often make simplifications or restrict the choice of treatments. Examples of simplifications are neglecting natural regeneration that appears on a plantation site, omitting advance regeneration in simulations, or restricting thinning treatments to low thinning (thinning from below).

Methods: This study analyzed the impacts of simplifications on the optimization results for Fennoscandian boreal forests. Management of pine and spruce plantations was optimized by gradually reducing the number of simplifying assumptions.

Results: Forced low thinning, cleaning the plantation from the natural regeneration of mixed species and ignoring advance regeneration all had a major impact on optimization results. High thinning (thinning from above) resulted in higher NPV and longer rotation length than thinning from below. It was profitable to leave a mixed stand in the tending treatment of young plantation. When advance regeneration was taken into account, it was profitable to increase the number of thinnings and postpone final felling. In the optimal management, both pine and spruce plantation was gradually converted into uneven-aged mixture of spruce and birch.
\end{abstract}

Conclusions: The results suggest that, with the current management costs and timber price level, it may be profitable to switch to continuous cover management on medium growing sites of Fennoscandian boreal forests.

Keywords: Plantation management; Continuous cover forestry; Even-aged management; Mixed stands

\section{Background}

Most silvicultural instructions have been developed for one-species even-aged stands (e.g., Anonym 2006). In the best case these instructions are based on simulations and optimizations. If optimization is used the instructions should show the best possible management for a certain objective function. However, caution may be necessary when applying the developed instructions in forestry practice. This is because the models used in calculations may not accommodate all relevant elements of stand dynamics, or the solved optimization problems may simplify reality. The growth and yield models or the optimization problems may be restricted to even-aged stands, uneven-aged stands, one-species stands, low thinnings, etc. It is not uncommon that some important elements of stand dynamics like advance regeneration are ignored when stand development is simulated (e.g., Valsta 1992; Pukkala and Miina 1997).

\footnotetext{
* Correspondence: timo.pukkala@uef.fi

${ }^{1}$ Faculty of Science and Forestry, University of Eastern Finland, P.O. 111, 80101 Joensuu, Finland

Full list of author information is available at the end of the article
}

Several growth and yield simulators are driven by a model that predicts dominant height as a function of stand age and site index (e.g., Shater et al. 2011; Guzmán et al. 2012). Use of the dominant height model assumes that dominant height is not reduced in thinning. Therefore, high thinnings are ruled out also from simulations and optimizations (e.g., Palahí and Pukkala 2003; Pasalodos-Tato et al. 2009). Because of this, it is not known whether the solutions of the optimization problems really indicate the optimal stand management. Several studies suggest that high thinnings may be better than low thinnings when economic profitability is maximized (e.g., Haight et al. 1985; Haight and Monserud 1990; Hyytiäinen et al. 2005).

Most optimizations have been done for pure one-species stands (e.g., Hyytiäinen et al. 2004; 2005; Tahvonen 2011). However, many stands and plantation sites get natural regeneration of several species (Miina and Saksa 2006, 2008). There may also be advance regeneration from the previous rotation which remains alive after clear-felling. Therefore, it is often possible to obtain a mixed stand even when only one species is planted. The possibility to utilize

\section{슬}

C 2014 Pukkala; licensee Springer. This is an Open Access article distributed under the terms of the Creative Commons Attribution License (http://creativecommons.org/licenses/by/2.0), which permits unrestricted use, distribution, and reproduction in any medium, provided the original work is properly cited. 
naturally regenerated admixtures of secondary species is seldom taken into account in optimization. Since the amount of natural regeneration is hard to predict it is often assumed that it does not exist, or it is supposed that seedlings other than the planted ones are removed in the tending treatments of the young plantation. Sometimes the growth and yield model, or the problem formulation used in optimization, has been developed for one-species stands, which means that admixtures of other species must be ignored because of "technical" reasons. Even if the model accommodates several species it may not describe the interactions between species in a proper way.

Advance regeneration is seldom predicted in the optimizations for even-aged stands. However, if regeneration and ingrowth are plentiful, they may have a major impact on the optimal stand management. It might be more profitable to release the understorey trees instead of clearcutting all trees and establishing a new stand by planting. The reason for ignoring ingrowth may be the lack of recruitment models or a belief that it is an insignificant element of stand dynamics. However, understory reinitiation is a well recognized stage of the natural dynamics of boreal forests (Oliver and Larson 1996). Sooner or later, natural regeneration begins to appear in all even-aged boreal stands. Both the start and the speed of regeneration depend on overstorey management. If the overstorey consists of shade-intolerant pioneer species, such as pine (Pinus sylvestris), aspen (Populus tremula) and birch (Betula pendula and B. pubescens), more shade-tolerant species like spruce (Picea abies) typically appear in the stand as understorey. This kind of gradual species succession often begins at quite a young age.

This study analyzed the consequences of the simplifying assumptions listed above in the management of boreal forests. The aim was to find out how the picture about optimal stand management changes when the restrictions and simplifications are gradually removed. Do numerically derived proposals for optimal management change when more realism is added to optimization and to the simulation of stand dynamics? This question was analyzed in spruce and pine plantations established on medium site in Central Finland.

\section{Methods}

Existing models for recruitment, tree growth and survival were used to simulate stand dynamics in alternative management schedules. The amount of established regeneration in a plantation site was predicted with the models of Miina and Saksa (2006, 2008). Their models predict the number of surviving individuals of the plantation species, as well as the amounts of natural regeneration of pine, spruce, birch, and hardwoods other than birch. The prediction depends on site characteristics, site preparation method and the used regeneration method (planting, sowing, or natural regeneration from seed or shelter trees).

In addition to the number of seedlings, the models of Miina and Saksa also predict the mean height of the seedlings three years after planting. Since the residual standard deviations of the height models are also reported, it is possible to generate initial size variation among seedlings. In this study, 15 seedlings of different sizes (15 size classes) were generated to represent the planted species (spruce or pine). In addition, 5 seedlings were generated to represent the other conifer (pine or spruce), 5 seedlings for silver birch (B. pendula), 5 seedlings for pubescent birch (B. pubescent), and 5 seedlings for hardwoods other than birch. As a result, a 3-year-old seedling stand corresponding to an average conifer plantation on medium site was obtained.

A tending treatment was simulated at the age of 7 years. It was first assumed that species other than the planted one are completely removed. Then, other optimizations were conducted in which a mixture of pine, spruce and birch was left to continue growing. Hardwoods other than birch were removed completely. Trees were left in all size classes of the plantation species but smaller classes were thinned more than larger ones. Other species were treated with uniform thinning. As a result, the tending treatment reduced the size variation of seedlings only slightly. The tending of the spruce plantation left 330 pines, 1028 spruces, 330 silver birches and 330 pubescent birches per hectare. In the pine plantation, 1525 pines, 300 spruces, 90 silver birches and 90 pubescent birches were kept. The number of birches was lower because of the adverse effect of a dense birch cover on pine development. This is because birches easily overtop pines, which reduces the productivity of the stand. This was also noted in preliminary simulations.

The further development of trees was predicted with the models of Pukkala et al. (2013). Their model set consists of individual-tree diameter increment model, individual-tree survival model, and models for ingrowth. The ingrowth models are based on stands in which the basal-area-weighted mean diameter is at least $10 \mathrm{~cm}$. Accordingly, in the simulations of this study, ingrowth was predicted once the mean tree diameter exceeded $10 \mathrm{~cm}$. Species interactions are included in all models. The diameter increment models predict, among other things, that pine and birch competitors reduce the growth of spruce less than spruce competitors. The ingrowth models predict spruce ingrowth also in pure pine and birch stands, which corresponds to the natural dynamics of boreal forests.

The assortment volumes of removed trees were calculated using the taper models of Laasasenaho (1982). Tree height was required in volume calculations and it was 
predicted with the models of Pukkala et al. (2009). The top diameters of timber assortments were as follows:

- Pine: $15 \mathrm{~cm}$ for saw $\log , 8 \mathrm{~cm}$ for pulpwood

- Spruce: $16 \mathrm{~cm}$ for saw $\log , 8 \mathrm{~cm}$ for pulpwood

- Birch: $16 \mathrm{~cm}$ for saw log, $9 \mathrm{~cm}$ for pulpwood

The crosscutting of each removed tree was simulated, taking into account the minimum piece lengths of different timber assortments. A certain percentage of saw log volume was moved to the pulpwood component to mimic the effect of quality defects. The deduction in saw $\log$ volume was $10 \%$ for pine, $5 \%$ for spruce, $15 \%$ for silver birch and $20 \%$ for pubescent birch.

Roadside timber prices were used to calculate the income from harvests. The roadside prices were $60 € / \mathrm{m}^{3}$ for pine and spruce saw $\log , 50 € / \mathrm{m}^{3}$ for birch saw $\log$, and $30 € / \mathrm{m}^{3}$ for pulpwood. To calculate net income, harvesting costs were subtracted from the roadside value of harvested trees. The models of Valsta (1992) were used. According to these models the harvesting cost per removed cubic meter decreases with increasing mean size of harvested trees and increasing volume $\left(\mathrm{m}^{3} / \mathrm{ha}\right)$ of the harvest. Thinnings have a higher harvesting cost per cubic meter than clear-felling if the removed volume and mean size of removed trees are the same. Stand establishment cost in year 0 was $1400 € /$ ha. The tending cost in year 7 depended on the number and diameter of the removed seedlings, but it was close to $270 € /$ ha in all cases.

A set of optimizations was done for spruce and pine plantations growing on medium site (mesic site, Myrtillus type). This site type is by far the most common fertility class in the southern part of Finland, covering almost 50\% of productive forest land. All the main tree species of Finland grow well in this site, making it possible to manage the forest in many different ways.

The following set of optimizations was as conducted:

1. All species except the planted one were removed in the tending treatment of the young stand; two thinnings were conducted during the rotation; at most $40 \%$ of stand basal area could be removed in thinning; thinnings were conducted as low thinning.

2. Otherwise the same but thinning type was not restricted to low thinning.

3. Otherwise similar to alternative 2 except that thinning intensity was not restricted.

4. Otherwise similar to alternative 3 except that a mixture of pine, spruce, silver birch and pubescent birch was left in the tending treatment of the young stand (at year 7).

5. Otherwise similar to alternative 4 except that ingrowth was simulated and the number of thinnings was increased from two to three.
6. Otherwise similar to alternative 5 except that the number of thinnings was increased from three to four.

7. Otherwise similar to alternative 6 except that the number of thinnings was increased from four to five.

Two thinnings were used in alternatives $1-4$ since it has been found that additional thinnings no longer increase the net present value when stand management is optimized without simulating ingrowth (e.g., Pukkala 2006). Alternative 1 corresponds to optimizing the type silviculture that was recommended in Finland for several decades (Anonym 2006). High thinning was forbidden and thinnings could not be too heavy. In the optimization, low thinning was forced by penalizing the solution if the mean tree diameter increased less than 5\% as the result of thinning.

Alternative 2 reflects the current situation in which high thinning is permitted but there are regulations that prevent very heavy thinnings. Alternative 3 is a step forward to greater freedom and flexibility, and it may lead to solutions that violate the current forest law of Finland. Henceforth, alternative 1 is referred to as the "low-thinning" alternative and the other alternatives are called as "free-thinning" alternatives.

Alternative 4 recognizes the fact that developing mixed stands is often possible even if only one species was planted. Alternatives 5-7 reflect the recent acceptance and increased use of continuous cover management. They allow selective felling and developing the new tree generation from advance regeneration.

The type of thinning was included in the optimization problems by specifying the harvest percentage separately for three different diameter classes. The classes were $10-14 \mathrm{~cm}, 14-20 \mathrm{~cm}$ and $>20 \mathrm{~cm}$ for conifers and 10$16 \mathrm{~cm}, 16-22 \mathrm{~cm}$ and $>22 \mathrm{~cm}$ for birch. The classification was based on calculations of the absolute and relative value increments of different tree sizes. Trees less than $10 \mathrm{~cm}$ in dbh have very high relative value increment during the coming 5-15 years. On the other hand, the road side value of these trees is small and their harvesting is costly. Therefore, it was assumed that trees smaller than $10 \mathrm{~cm}$ should never be removed in thinnings. Another diameter class for which the value increment is good is 14-20 cm for conifers and 16-22 cm for birches. This is because trees of this size are approaching the saw log size and their value will therefore increase rapidly. The remaining two diameter classes, 10-14 am (10-16 cm in birch) and $>20 \mathrm{~cm}(>22 \mathrm{~cm})$, have much lower relative value increments, which means that removing trees from these classes does not reduce the value increment of the stand as much as cutting trees that are approaching a value threshold. 
Table 1 Net present value calculated with $3 \%$ discount rate and optimal rotation length in the optimizations conducted for spruce plantation

\begin{tabular}{|c|c|c|c|c|}
\hline \multirow[t]{2}{*}{ Optimization problem } & \multicolumn{2}{|c|}{ NPV, $€ /$ ha } & \multicolumn{2}{|c|}{ Rotation length, yrs } \\
\hline & $10 \%$ damage & $40 \%$ damage & $10 \%$ damage & $40 \%$ damage \\
\hline 1 Low thinning max $40 \%$ & \multicolumn{2}{|c|}{408} & \multicolumn{2}{|c|}{73} \\
\hline 2 Free thinning max $40 \%$ & \multicolumn{2}{|c|}{651} & \multicolumn{2}{|c|}{92} \\
\hline 3 Free thinning no limit & \multicolumn{2}{|c|}{845} & \multicolumn{2}{|c|}{101} \\
\hline 4 Mixed stand & \multicolumn{2}{|c|}{1088} & \multicolumn{2}{|c|}{88} \\
\hline 5 Ingrowth, 3 thinnings & 1137 & 1107 & 126 & 118 \\
\hline 6 Ingrowth, 4 thinnings & 1187 & 1116 & 128 & 139 \\
\hline 7 Ingrowth, 5 thinnings & 1228 & 1153 & 131 & 171 \\
\hline
\end{tabular}

When ingrowth was simulated, either $10 \%$ or $40 \%$ of understorey trees were assumed to be damaged in a thinning treatment.

Based of this rationale, a thinning treatment was specified with three harvest percentages that were optimized separately for pine, spruce, silver birch and pubescent birch. The number of years since planting (first thinning) or previous cutting (other thinnings) defined the timing of the thinning treatment. Therefore, the number of optimized decision variables was $13(4 \times 3+1)$ for each thinning treatment and 1 for the final felling (number of years since the last thinning). A management schedule with 5 thinnings included $5 \times 13+1=66$ optimized variables.
The used optimization method was the direct search algorithm proposed by Hooke and Jeeves (1961). In each problem, the direct search was repeated 10 times and the best solution was selected. Every search was started from the best of 100-700 random combinations on decision variables. The number of random searches was increased with increasing number of optimized variables. NPV to infinity (i.e., soil expectation value) with $3 \%$ discount rate was maximized in all problems. When calculating the NPV, it was assumed that rotations similar to the simulated one are repeated to infinity.
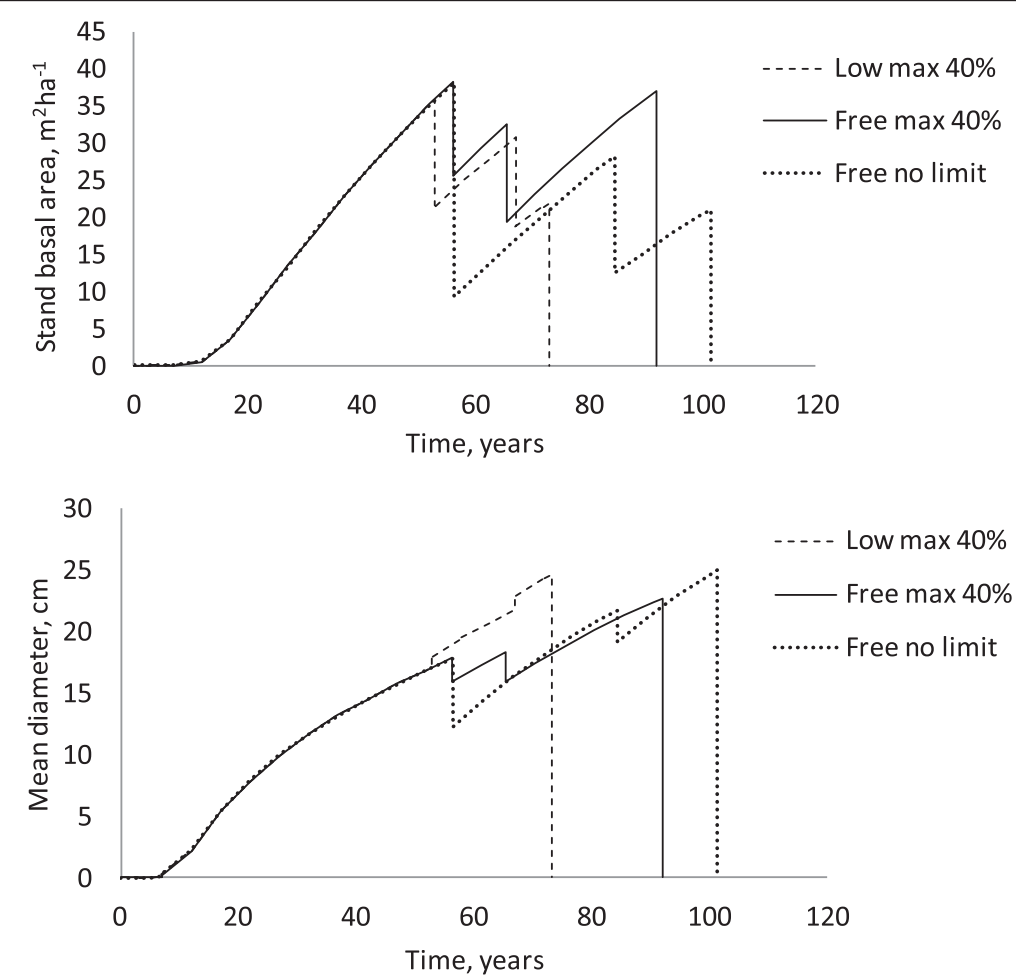

Figure 1 Development of stand basal area and mean tree diameter (dbh) in a pure spruce stand when only low thinning is allowed, or high thinning is allowed with and without $40 \%$ maximum thinning intensity. 


\section{Results and discussion \\ Spruce}

Optimizations for spruce plantations indicated that high thinnings lead to greater net present value than low thinnings (Table 1). Optimal rotation length increased from 73 to 101 years when non-restricted free thinning was used instead of thinning at most $40 \%$ from below. Especially the first high thinning in the unrestricted alternative was very heavy decreasing stand basal area from 38 to $10 \mathrm{~m}^{2} \mathrm{ha}^{-1}$ and mean tree diameter from 18 to $12 \mathrm{~cm}$ (Figure 1). Clear-felling was conducted at the same mean diameter $(25 \mathrm{~cm})$ in both the low-thinning and the unrestricted free-thinning alternatives (Figure 1). This suggests that financial maturity of the dominant tree layer dictates the timing of final felling instead of stand age. It can be concluded that, with stand basal areas of $20-25 \mathrm{~m}^{2} \mathrm{ha}^{-1}$, the value increment of the stand falls below the $3 \%$ opportunity cost of land and growing stock (0.03 times the value of bare land plus the value of growing stock) approximately when the trees reach $25-\mathrm{cm}$ breast height diameter. In alternative 2 (free thinning at most $40 \%$ of stand basal area) the clearfelling diameter was smaller because the stand basal area was larger.
Optimization for the mixed seedling stand resulted in higher NPVs and shorter rotation length than the optimal management of pure stand (Table 1). It was optimal to remove all birches in the first commercial thinning and most pines in the second thinning (Figure 2). Both thinnings were high thinnings since species having the largest diameters were thinned most (silver birch in the first thinning, pine in the second thinning). In addition, both pines and spruces were thinned from above in the second thinning. As a consequence, the mean tree diameter decreased from 17.4 to $16.0 \mathrm{~cm}$ in the first thinning, and from 21.1 to 17.4 in the second thinning. Almost no spruce was removed in the first thinning since spruces were clearly smaller than pines and silver birches. Pubescent birches were removed in the first thinning although they were not larger than spruces. This is because the growth of pubescent birch starts to decline sooner than the growth of conifers.

Optimizations in which ingrowth was simulated resulted in higher NPVs than obtained in any previous optimization (Table 1). The more there were thinnings, the higher was the NPV and the longer was the rotation length. NPV decreased when assuming a 40\% damage rate among understorey trees, instead of $10 \%$, but even
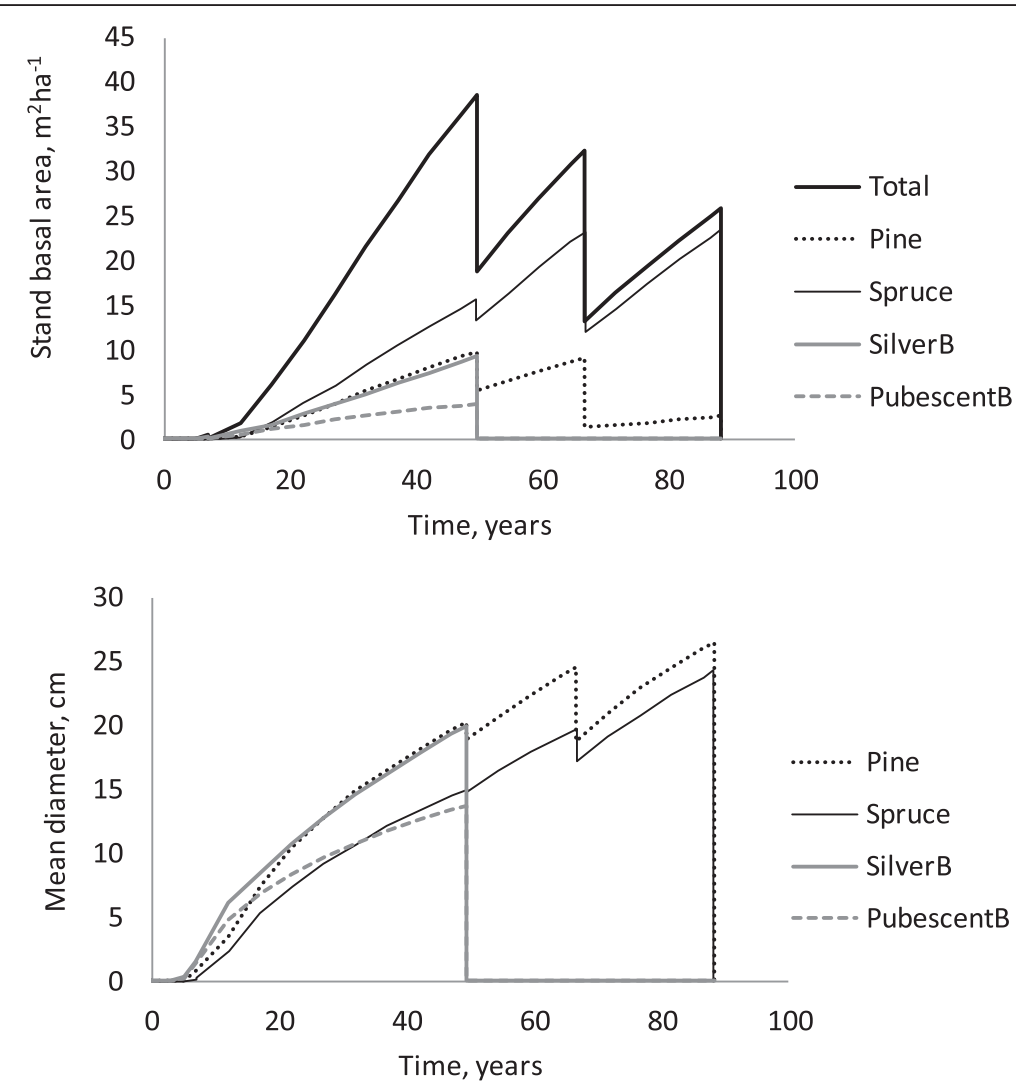

Figure 2 Development of stand basal area and mean tree diameter (dbh) in a spruce plantation when a mixture of pine, spruce and birch is left in the tending of young stand (optimization problem 4). 
with $40 \%$ damage rate the profitability was better than in schedules where ingrowth was ignored. Figure 3 shows the optimal management with 5 thinnings and 10\% damage rate. All birches that were left in young stand tending were removed in the first commercial thinning and pines were gradually removed in the first three thinnings. Ingrowth began at about 30 years, and most ingrowth was spruce and pubescent birch. Since there was no pine ingrowth, pine disappeared completely from the stand in the third thinning. After the fourth thinning, this mixed stand of spruce and birch had nearly the same number of birches and spruces. However, most of stand basal area was in spruce (Figure 3) suggesting that birches remained in lower canopy layers. There was increased birch ingrowth after every thinning but the number of birches stopped increasing a few years later because of decreased ingrowth and increased mortality.

\section{Pine}

In pine, the optimal rotation length increased from 64 to 80 years when high thinnings were allowed and thinning intensity was not restricted (Table 2). NPV increased from 847 to $1415 € /$ ha. Similarly as in spruce, the mean diameter at clear-felling was the same in low thinning and unrestricted free-thinning schedules, $25.5 \mathrm{~cm}$ (Figure 4). Increasing stand basal area decreased the optimal clearfelling diameter ("Free max 40\%" in Figure 3). When high thinning was allowed the first thinning was clearly later resulting in larger removal and clearly higher net income. The net income of the first commercial cutting was only $787 € /$ ha in the low-thinning alternative whereas it was 3387 and $5188 € /$ ha, respectively, in the restricted and unrestricted free-thinning alternative. The low-thinning alternative removed only pulp wood. In the free-thinning alternatives, $1 / 3$ of the removed volume of the first commercial cutting was saw log. Allowing high thinning reduced the harvesting cost per cubic meter by $25 \%$.

It was profitable to leave an admixture of spruces and birches in the tending of young stand. The NPV improved by $9 \%$ as compared to the unrestricted free-thinning alternative of a pure pine stand (Table 2). Similarly to spruce, all birches were removed in the first thinning (Figure 5).
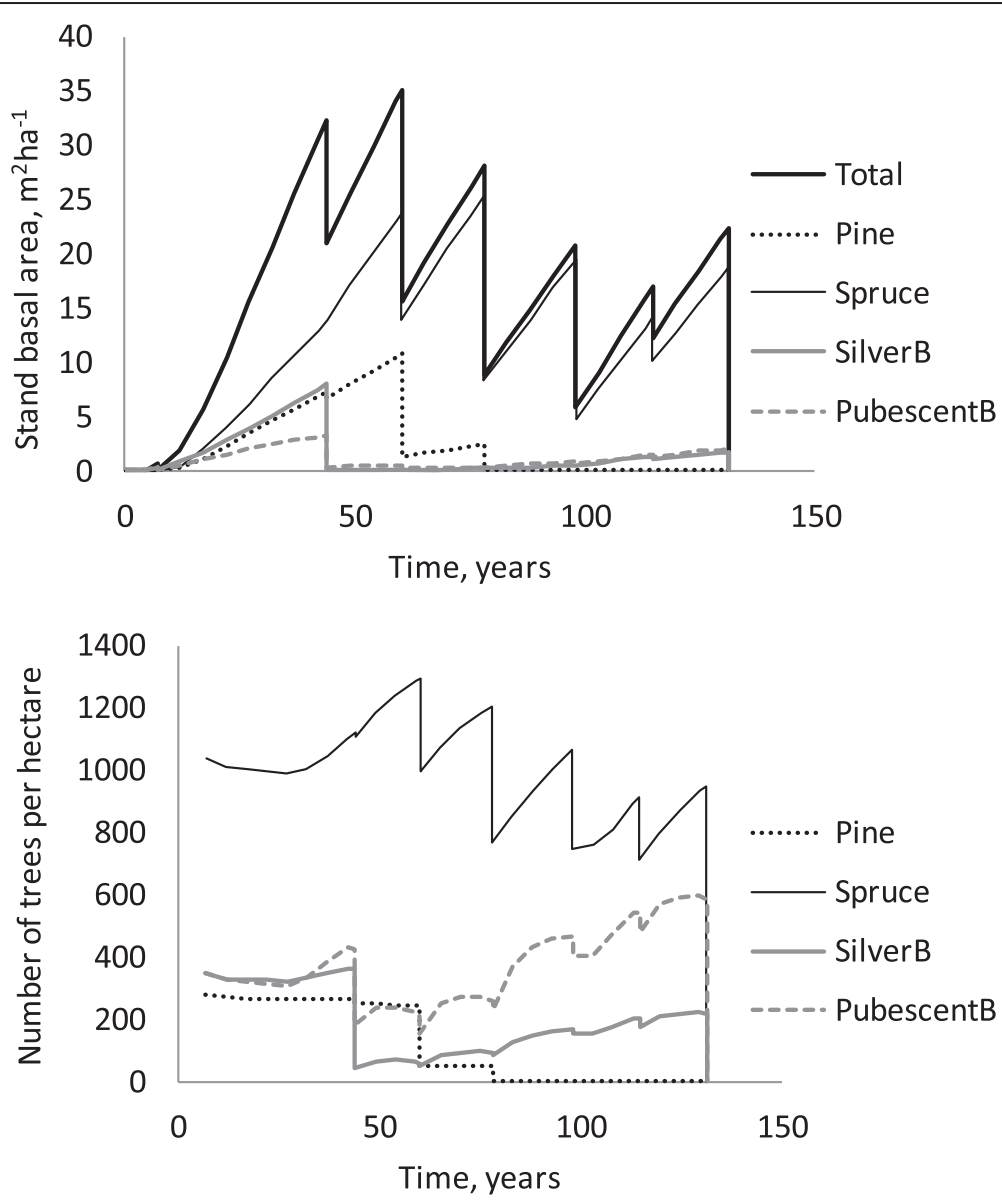

Figure 3 Development of stand basal area and number or trees per hectare in a spruce plantation when a mixture of pine, spruce and birch is left in the tending of young stand and advance regeneration is simulated (optimization problem 7 with $10 \%$ damage). 
Table 2 Net present value calculated with 3\% discount rate and optimal rotation length in the optimizations conducted for pine plantation

\begin{tabular}{|c|c|c|c|c|}
\hline \multirow[t]{2}{*}{ Optimization problem } & \multicolumn{2}{|c|}{ NPV, $€ /$ ha } & \multicolumn{2}{|c|}{ Rotation length, yrs } \\
\hline & $10 \%$ damage & $40 \%$ damage & $10 \%$ damage & $40 \%$ damage \\
\hline 1 Low thinning max $40 \%$ & \multicolumn{2}{|c|}{847} & \multicolumn{2}{|c|}{64} \\
\hline 2 Free thinning max $40 \%$ & \multicolumn{2}{|c|}{1190} & \multicolumn{2}{|c|}{76} \\
\hline 3 Free thinning no limit & \multicolumn{2}{|c|}{1415} & \multicolumn{2}{|c|}{80} \\
\hline 4 Mixed stand & \multicolumn{2}{|c|}{1539} & \multicolumn{2}{|c|}{78} \\
\hline 5 Ingrowth, 3 thinnings & 1598 & 1597 & 112 & 113 \\
\hline 6 Ingrowth, 4 thinnings & 1659 & 1640 & 126 & 130 \\
\hline 7 Ingrowth, 5 thinnings & 1663 & 1649 & 137 & 125 \\
\hline
\end{tabular}

When ingrowth was simulated, either $10 \%$ or $40 \%$ of understorey trees were assumed to be damaged in a thinning treatment.

The rest of the removal was pine. Since the second thinning removed more pines than spruces, the stand was gradually converted into a mixture of pines and spruces where the basal area of pine was not much higher than the basal area of spruce. The heavy high thinning of pine in the first cutting almost removed the size difference between pine and spruce. In the second thinning, the mean diameter of both pine and spruce decreased (Figure 5). This means that the thinning rate was higher among large trees than among small ones.

When ingrowth was simulated and the number of thinnings was increased, NPV and rotation length increased
(Table 2). There was not much difference in NPV between $10 \%$ and $40 \%$ understorey damage rates. Figure 6 suggests that the third thinning removed most of the first tree generation implying that the treatment was in fact overstorey removal. The mean diameter decreased from 21.2 to $8.5 \mathrm{~cm}$. All birches except the small ingrowth trees were removed in the first thinning. Half of pines were removed in the first thinning and the rest were removed in two subsequent thinnings. Almost no spruce was removed before the third thinning. As a result, the stand was gradually converted into birch-spruce mixture, in which spruce accounted for most of the stand basal area. There
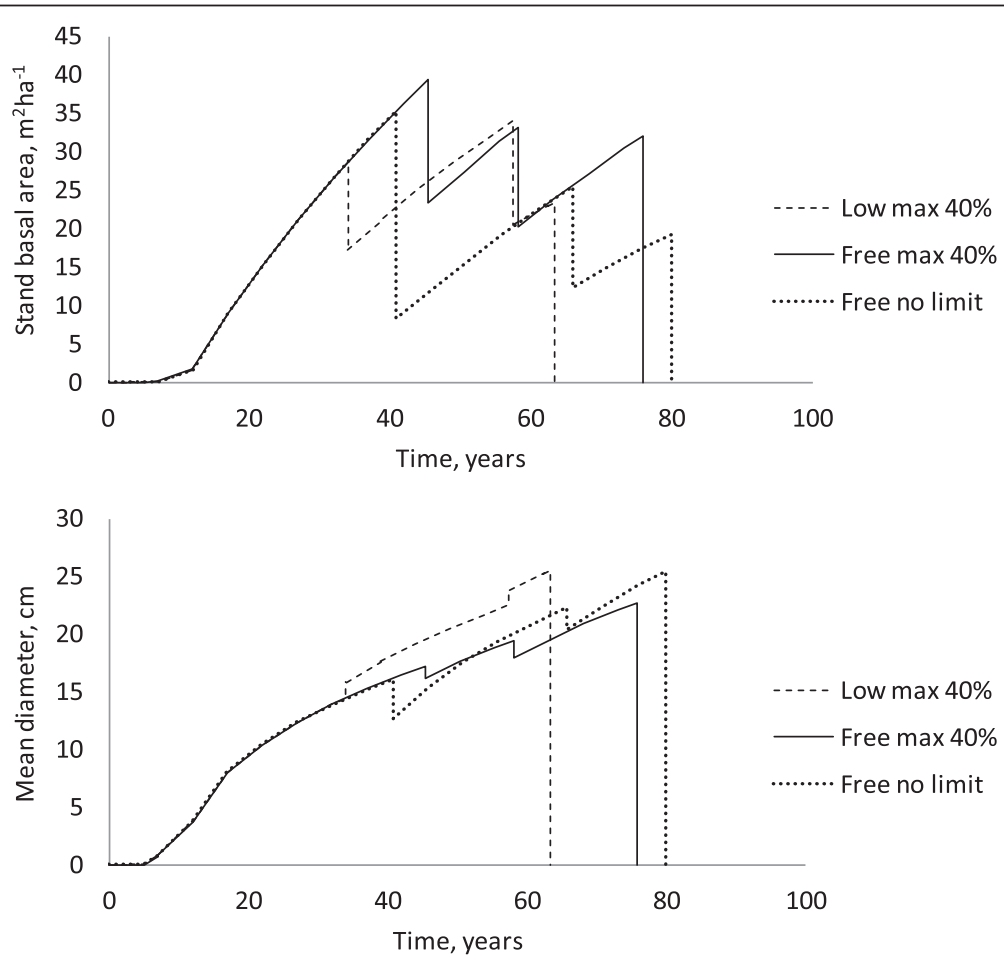

Figure 4 Development of stand basal area and mean tree diameter (dbh) in a pure pine stand when only low thinning is allowed, or high thinning is allowed with and without $40 \%$ maximum thinning intensity. 

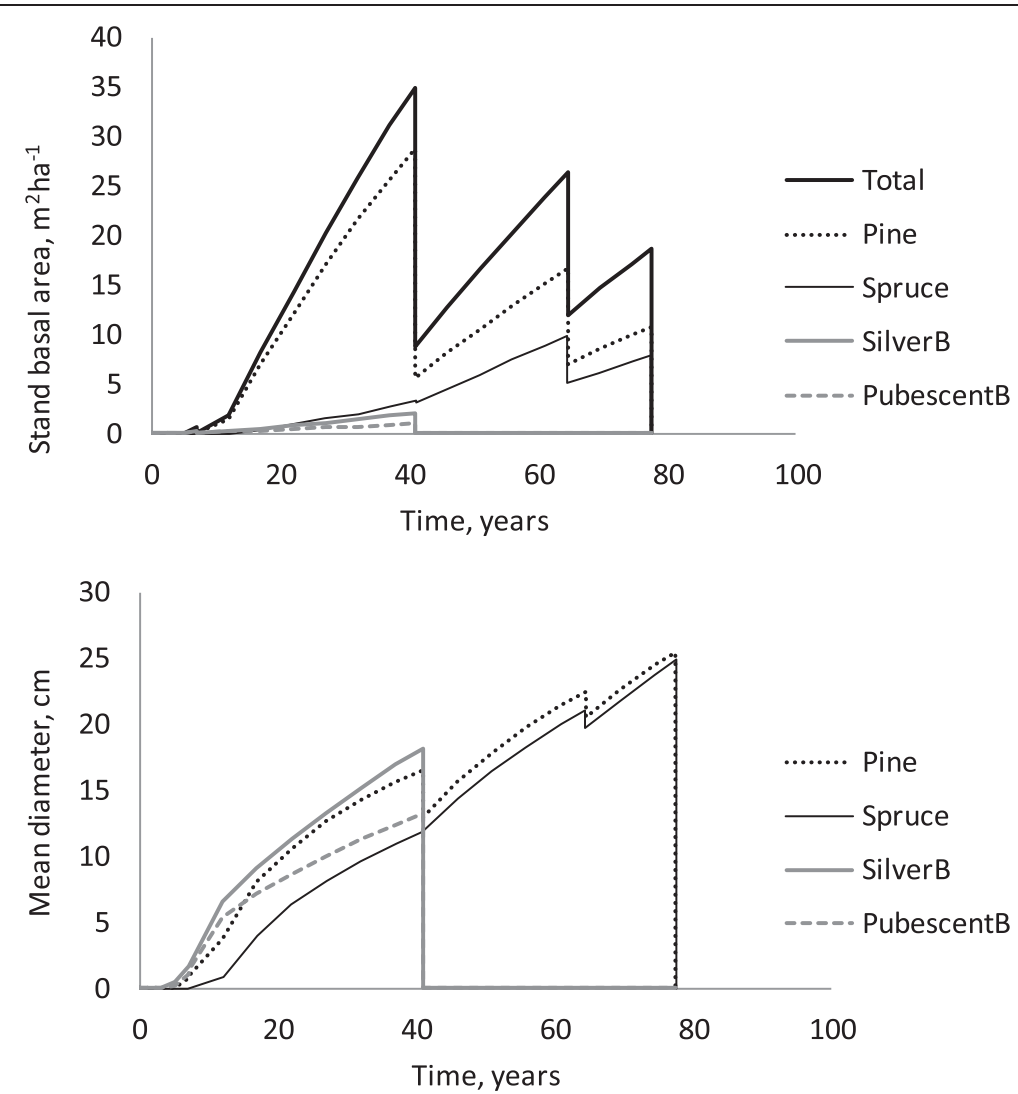

Figure 5 Development of stand basal area and mean tree diameter (dbh) in a pine plantation when a mixture of pine, spruce and birch is left in the tending of young stand (optimization problem 4).

was both spruce and birch ingrowth but spruces grew faster than birches, which had difficulties to penetrate to the dominant canopy layer. The ending stand structure of the pine plantation was fairly similar as the ending structure of the spruce plantation - both were converted into a mixture of birch and spruce, which was treated with repeated high thinnings.

\section{Conclusions}

The study presented the first optimizations for pine, spruce and birch mixtures in Finland. Most previous optimizations are for pure one-species stands (Valsta 1992; Hyytiäinen et al. 2004; Tahvonen 2011), and there are some studies for pine-spruce mixtures (Pukkala and Miina 1997; Pukkala et al. 1998; Vettenranta and Miina 1999). The latter studies suggest that pine and spruce mixtures are more productive than pure conifer stands. Optimizations for mixed stands also suggest that mixtures may be healthier than monocultures (Möykkynen and Pukkala 2010). They are also better than monocultures in terms of diversity and scenic value (Silvennoinen et al. 2001). Although yield was not maximized in the current study, the optimizations suggest that mixed stands may be more productive than pure spruce stands. When ingrowth was not included in simulation, the mixed spruce plantation produced $8.7 \mathrm{~m}^{3} \mathrm{ha}^{-1} \mathrm{a}^{-1}$ whereas the most productive pure stand (free thinning at most $40 \%$ of basal area) produced $7.8 \mathrm{~m}^{3} \mathrm{ha}^{-1} \mathrm{a}^{-1}$. In the pine plantation, mixed stands were not more productive than a pure pine stand.

This study is also the first one in which advance regeneration was taken into account in the optimization of even-aged stand management. Considering advance regeneration in the analysis has a major impact on the results. It was shown that simplifying assumptions in simulation and optimization may lead to biased conclusions about optimal forest management. It seems that the optimal management of a conifer plantation involves using repeated high thinnings and relying on advance regeneration instead of clear-felling and planting. The maximum number of thinnings tested in this study was five, but most probably the NPV would continue increasing with increasing number of thinnings, implying that it would be optimal to switch to continuous cover management. However, the effect of additional thinnings on NPV would be very small since net incomes discounted from distant future would have only a negligible effect on the total NPV. 

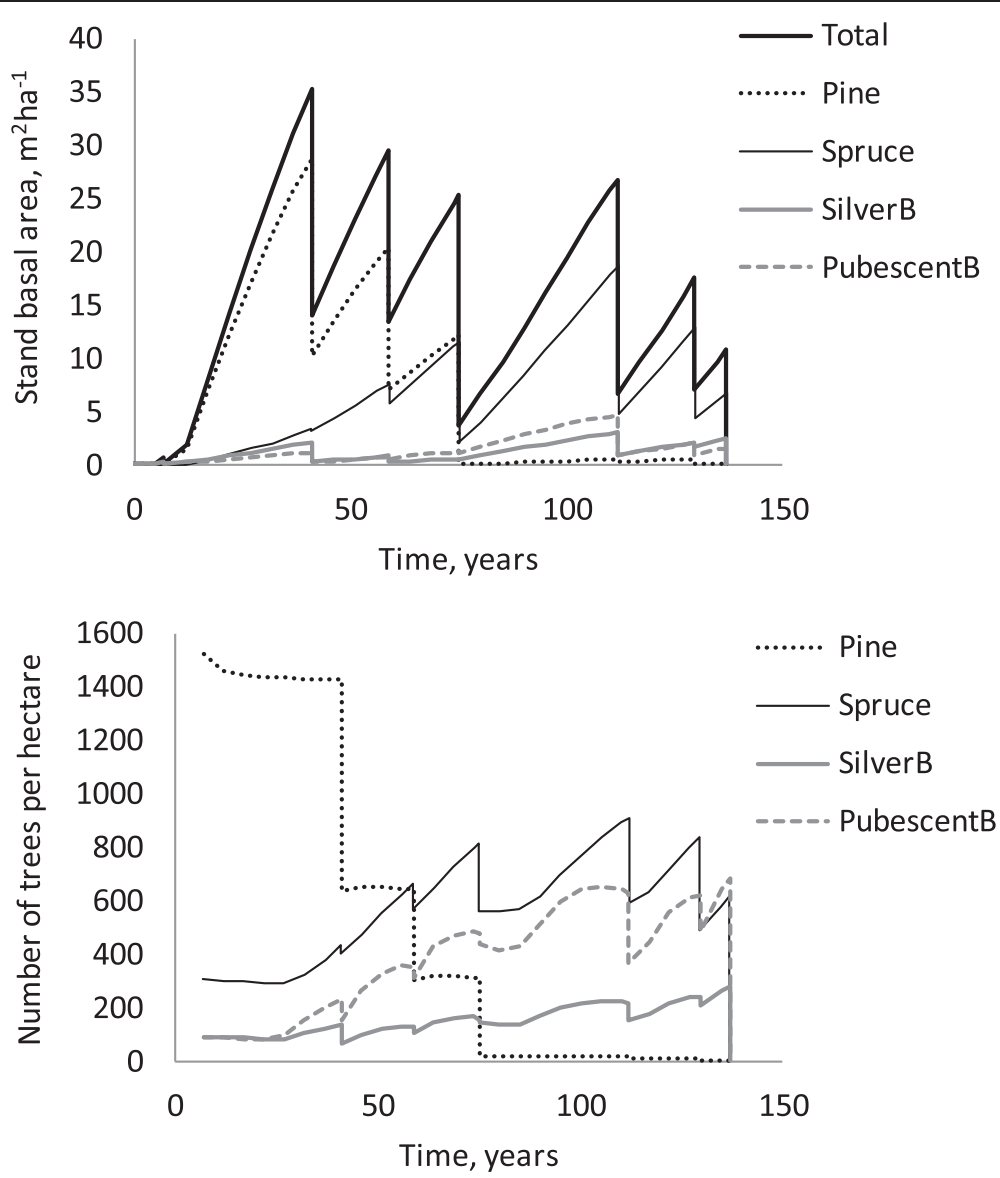

Figure 6 Development of stand basal area and number or trees per hectare in a pine plantation when a mixture of pine, spruce and birch is left in the tending of young stand and advance regeneration is simulated (optimization problem 7 with $10 \%$ damage).

The optimizations of this study showed that the first commercial thinning of an even-aged stand should be conducted later than recommended in the thinning guidelines (Anonym 2006), at a basal area of 35$40 \mathrm{~m}^{2} \mathrm{ha}^{-1}$. The current recommendation is to thin at 25-28 m $\mathrm{ma}^{-1}$. The result agrees with previous research which suggests that the first thinning should be conducted when the stand density is near the self thinning limit (Pukkala and Miina 1998; Vettenranta and Miina 1999; Hyytiäinen et al. 2004, 2005). Earlier thinning, in which only pulpwood is removed, results in a low net return.

The result that high thinning is more profitable than low thinning agrees with several previous studies (Roise 1986; Solberg and Haight 1991; Valsta 1992; Pukkala and Miina 1998; Hyytiäinen et al. 2005). In this study, unrestricted free thinning resulted in 67\% (pine) to $166 \%$ (spruce) increase in NPV as compared to the optimal low-thinning alternative. Hyytiäinen and Tahvonen (2001, 2003) found that the economic loss to forest landowner may be substantial if official silvicultural instructions are followed instead of the optimal management. The relative differences would most probably be smaller if lower discount rate was used.

Also this study simplified the simulation of stand development and the optimization problem in a few ways. One simplification was that growth variation around model prediction was not simulated, although it would have an impact on the simulation results (Miina 1993; Pukkala et al. 2013). The main influence would be faster differentiation and wider variation of tree size. The consequences of this simplification were reduced by generating size variation in the initial stand. Initial size variation led to the differentiation of tree size, even though residual variation was not simulated. However, differentiation would have been faster if residual variation had been simulated.

It was assumed that ingrowth rate was equal to the model prediction although in reality there is much temporal and spatial variation in regeneration and ingrowth. Simulating regeneration in a stochastic way would correspond better to what happens in nature. However, this would have lead to stochastic optimization, which will be the topic of future studies. The results of this study apply to sites in which the 
ingrowth is fairly constant and near the average or normal level. Optimal management would be different for stands where ingrowth deviates from this level. However, the small difference between optimization results for $10 \%$ and $40 \%$ undestorey damage rates suggests that the results are not highly sensitive to the level of ingrowth. Moreover, understorey trees revive at different rates and their growth rate varies much. As a result, temporally irregular regeneration may provide a fairly constant supply of understorey trees to upper canopy layers.

The models that were used in growth simulation (Pukkala et al. 2013) did not describe the thinning effect explicitly; post-thinning growth was predicted using the post-thinning values of tree and stand characteristics. Previous research suggests that released spruce understoreys may need 4 to 5 years to fully adapt to the new conditions (Metslaid et al. 2005). Therefore, there is a possibility that the post-thinning growth was over-estimated after heavy high thinnings. The significance of this possibility was analyzed by conducting simulations in which the growth of a high-thinning spruce stand was reduced during 5 post-thinning years by decreasing the random stand effect of the diameter increment model (by two standard deviations). Twenty-year volume growth was reduced by $11 \%$ but 30 -year growth was only $4 \%$ smaller as compared to simulation without growth reduction. Slower initial growth means that competition increases slower resulting in faster growth during later 5 -years periods.

About $22 \%$ of observations behind the used diameter increment model came from a silvicultural experiment in which heavy high thinning was the most common treatment. In addition, a majority of the growth observations of this experiment represented immediate postthinning growth. In the other modeling data sources, the time since previous thinning varied in the same way as it varies in managed Finnish forests (0-40 years). Taking into account that spruce understoreys are usually vigorous under all canopies except a dense and pure spruce canopy, it may be concluded that the impact of thinning stress on the results of this study would remain rather small.

The optimization problem was formulated so that thinning intensity was specified for three diameter classes per tree species and thinning event. Several previous studies have also used three thinning intensities to specify and optimize the type of thinning (Valsta 1992; Pukkala and Miina 1997; Vettenranta and Miina 1999). Using a higher number of diameter classes may have improved the solutions slightly (Hyytiäinen et al. 2005) but, on the other hand, the optimization problem would have become more complicated.

All models and optimization problems simplify reality. Realism should be added as long as it has a significant influence on the results. Those steps that were taken in the current study were all shown to be significant, having a strong impact on our comprehension about the optimal management of boreal forests. Future studies will show whether further steps towards realism are necessary. One improvement, which would most probably have at least some effect, would be to integrate the risks associated to tree growth and survival, and possible changes in timber markets, in the optimization of stand management (Pukkala and Kellomäki 2012). Most probably these analyses would enhance the positive effects that mixed stands and uneven-aged stand structures have on the profitability of forestry (Rollin et al. 2005; Pukkala and Kellomäki 2012) since both are ways to share risks (among species, or among cutting events). It would also be interesting to analyze the influence of market trends on optimization results. The price of spruce pulp wood has shown a decreasing trend whereas the price of small-sized birch has increased (Anonym 2012). If the same trend continues, it would be profitable to increase the share of birch more than suggested in this study.

\section{Competing interests}

The authors declare that they have no competing interests.

\section{Authors' contributions}

TP conducted the optimizations. All authors participated in writing. All authors read and approved the manuscript.

\section{Author details}

${ }^{1}$ Faculty of Science and Forestry, University of Eastern Finland, P.O. 111, 80101 Joensuu, Finland. ${ }^{2}$ Joen Forest Program Consulting, Rauhankatu 41, 80100 Joensuu, Finland.

Received: 31 May 2013 Accepted: 4 October 2013

Published: 26 February 2014

\section{References}

Anonym (2006) Hyvän Metsänhoidon Suositukset. Metsätalouden Kehittämiskeskus Tapio. Metsäkustannus Oy, Helsinki, p 100

Anonym (2012) Finnish Statistical Yearbook of Forestry. The Finnish Forest Research Institute, Helsinki, p 450

Guzmán G, Pukkala T, Palahí M, de-Miquel S (2012) Predicting the growth and yield of Pinus radiata in Bolivia. Ann For Sci 69:335-343

Haight RG, Monserud RA (1990) Optimizing any-aged management of mixedspecies stands. II. Effects of decision criteria. For Sci 36:125-144

Haight RG, Brodie JD, Dahms WG (1985) A dynamic programming algorithm for optimization of lodgepole pine management. For Sci 31:321-330

Hooke R, Jeeves TA (1961) "Direct search" solution of numerical and statistical problems. J Assoc Comput Machine 8:212-229

Hyytiäinen K, Tahvonen O (2001) The effects of legal limits and recommendations on timber production: the case of Finland. For Sci 47:443-454

Hyytiäinen K, Tahvonen O (2003) Maximum sustained yield, forest rent of Faustmann: does it really matter? Scand J For Res 18:457-469

Hyytiäinen K, Hari P, Kokkila T, Mäkelä A, Tahvonen O, Taipale J (2004) Connecting process-based forest growth model to stand-level economic optimization. Can J For Res 34:2060-2073

Hyytiäinen K, Tahvonen O, Valsta L (2005) Optimum juvenile density, harvesting and stand structure in even-aged Scots pine stands. For Sci 51:120-133

Laasasenaho J (1982) Taper curve and volume equations for pine spruce and birch. Commun Inst For Fenn 108:1-74

Metslaid M, llisson T, Vicente M, Nikinmaa E, Jõgiste K (2005) Growth of advance regeneration of Norway spruce after clear-cutting. Tree Physiol 25:793-801

Miina J (1993) Residual variation in diameter growth in a stand of Scots pine and Norway spruce. For Ecol Manage 58:111-128 
Miina J, Saksa T (2006) Predicting regeneration establishment in Norway spruce plantations using a multivariate multilevel model. New For 32:265-283

Miina J, Saksa T (2008) Predicting establishment of tree seedlings for evaluating methods of regeneration for Pinus sylvestris, Scand. J For Res 23(1):12-27

Möykkynen T, Pukkala T (2010) Optimizing the management of Norway spruce and Scots pine mixtures on a site infected by Heterobasidion coll. Scand J For Res 40:347-356

Oliver CD, Larson BC (1996) Forest Stand Dynamics. John Wiley, Hoboken, New Jersey, p 520

Palahí M, Pukkala T (2003) Optimising the management of Scots pine (Pinus sylvestris L.) stands in Spain based on individual-tree models. Ann For Sci 60:105-114

Pasalodos-Tato M, Pukkala T, Castedo-Dorado F (2009) Models for the optimal management of Pinus radiata D. Don in Galicia (north-western Spain) under risk of fire. Allgemeine Forst- und Jagdzeitung 180:238-249

Pukkala T (2006) Puun hinta ja taloudellisesti optimaalinen hakkuun ajankohta. Metsätieteen aikakauskirja 1(2006):33-48

Pukkala T, Kellomäki S (2012) Anticipatory vs. adaptive optimization of stand management when tree growth and timber prices are stochastic. Forestry. doi:10.1093/forestry/cps043

Pukkala T, Miina J (1997) A method for stochastic optimization of stand management. For Ecol Manage 98:189-203

Pukkala T, Miina J (1998) Tree-selection algorithms for optimizing thinning using a distance-dependent growth model. Can J For Res 28:693-702

Pukkala T, Miina J, Kurttila M, Kolström T (1998) A spatial yield model for optimizing the thinning regime of mixed stands of Pinus sylvestris and Picea abies. Scand J For Res 13:31-42

Pukkala T, Lähde E, Laiho O (2009) Growth and yield models for uneven-sized forest stands in Finland. For Ecol Manage 258:207-216

Pukkala T, Lähde E, Laiho O (2013) Species interactions in the dynamics of evenand uneven-aged boreal forests. J Sust For 32(4):371-403

Roise JP (1986) An approach for optimizing residual diameter class distribution when thinning even-aged stands. For Sci 32:871-881

Rollin F, Buongiorno J, Zhou M, Peyron J-L (2005) Management of mixed-species, uneven-aged forests in the french Jura: from stochastic growth and price models to decision tables. For Sci 51(1):64-75

Shater Z, de-Miguel S, Kraid B, Pukkala T, Palahí M (2011) A growth and yield model for even-aged Pinus brutia ten. Stands in Syria. Ann For Sci 68:149-157

Silvennoinen H, Alho J, Kolehmainen O, Pukkala T (2001) Prediction models of landscape preferences at the forest stand level. Landscape Urban Plann 56(1-2):11-20

Solberg B, Haight RG (1991) Analysis of optimal economic management regimes for Picea abies stands using a stage-structured optimal-control model. Scand J For Res 6:559-572

Tahvonen O (2011) Optimal structure and development of uneven-aged Norway spruce forests. Can J For Res 41:2389-2402

Valsta L (1992) An optimization model for Norway spruce management based on individual-tree growth models. Acta For Fenn 232:20

Vettenranta J, Miina J (1999) Optimizing thinnings and rotation of Scots pine and Norway spruce mixtures. Silva Fenn 33(1):73-84

doi:10.1186/2197-5620-1-3

Cite this article as: Pukkala et al.: Stand management optimization - the role of simplifications. Forest Ecosystems 2014 1:3.

\section{Submit your manuscript to a SpringerOpen ${ }^{\circ}$ journal and benefit from:}

- Convenient online submission

- Rigorous peer review

- Immediate publication on acceptance

- Open access: articles freely available online

- High visibility within the field

- Retaining the copyright to your article

Submit your next manuscript at $\gg$ springeropen.com 